Arq. Bras. Med. Vet. Zootec., v.66, n.3, p.705-712, 2014

\title{
Avaliação da absorção colostral em neonatos ovinos da raça Bergamácia
}

[Evaluation of colostral absorption in neonates of Bergamacia breed]

\author{
C.M.V. Ulian', S. Fernandes², P.R.R. Ramos $^{3}$, A. Dias ${ }^{4}$, M.L.G. Lourenço ${ }^{2 *}$, S.B. Chiacchio \\ ${ }^{1}$ Aluna de pós-graduação - Faculdade de Medicina Veterinária e Zootecnia - Unesp - Botucatu, SP \\ ${ }^{2}$ Faculdade de Medicina Veterinária e Zootecnia - Unesp - Botucatu, SP \\ ${ }^{3}$ Instituto de Biociências - Unesp - Botucatu, SP \\ ${ }^{4}$ Faculdade de Medicina - Unesp- Botucatu, SP
}

\begin{abstract}
RESUMO
Objetivou-se determinar o período de absorção das macromoléculas colostrais e a transferência de imunidade passiva em cordeiros da raça Bergamácia. Avaliou-se o proteinograma sérico dos cordeiros antes da ingestão de colostro até 48 horas de vida e das frações colostrais ao nascimento e 12 horas pósparto. Foi avaliada a concentração de proteína total no soro por refratometria e sua relação com a densidade e quantidade de gamaglobulinas presentes no colostro. A concentração sérica de gamaglobulina nos cordeiros variou de $0,111 \pm 0,07 \mathrm{~g} / \mathrm{dL}$ antes da ingestão de colostro a 1,609 $\pm 0,72 \mathrm{~g} / \mathrm{dL}$ às 48 horas. Nas amostras de colostro, a concentração variou de $3,125 \pm 1,27 \mathrm{~g} / \mathrm{dL}$, imediatamente após o parto, para $1,378 \pm 0,82 \mathrm{~g} / \mathrm{dL}, 12$ horas após. A concentração de proteína sérica total teve acréscimo de 4,46 $\pm 0,58 \mathrm{~g} / \mathrm{dL}$ para $5,61 \pm 0,75 \mathrm{~g} / \mathrm{dL}$ entre o nascimento e após 48 horas, apresentando correlação positiva com a densidade e a proteína total colostral. A absorção colostral pelo cordeiro foi ascendente até 24 horas subsequentes ao parto, quando, então, iniciou-se sua estabilização. A quantificação da proteína sérica, com uso de refratômetro nos cordeiros, pode ser usada como método para avaliar a transferência de imunidade passiva, pois está diretamente relacionada com a absorção de gamaglobulina colostral.
\end{abstract}

Palavras-chave: cordeiros, eletroforese, gamaglobulina, transferência de imunidade passiva

\begin{abstract}
The period of absorption of colostrum macromolecules and the passive immunity transfer of Bergamacia lambs was determined. The serum proteinogram of lambs before the intake of colostrum up 48 hours of life and colostrum fractions between delivery and twelve hours after birth were measured. The total protein concentration in serum was evaluated by refractometry and also its relationship with the density and amount in colostrum. The serum concentration of gamma globulin in lambs from $0.111 \pm 0.07 \mathrm{~g} / \mathrm{dL}$ before the intake of colostrum was $1.609 \pm 0.72 \mathrm{~g} / \mathrm{dL}$ at 48 hours. In the colostrum samples, the concentration was $3.125 \pm 1.27 \mathrm{~g} / \mathrm{dL}$ immediately after delivery and $1.378 \pm 0.82 \mathrm{~g} / \mathrm{dL}$ twelve hours after birth. Serum total protein concentration increased from $4.46 \pm 0.58 \mathrm{~g} / \mathrm{dL}$ to $5.61 \pm 0.75 \mathrm{~g} / \mathrm{dL}$ between birth and after 48 hours, there was positive correlation with the density and total protein colostrum. The lamb had ascendant colostrum absorption subsequent to delivery, for twelve hours and then began its stabilization. The quantification of serum protein with the use of the refractometer in lambs can be used as a method to evaluate the transfer of passive immunity because it is directly related to the absorption of colostral gammaglobulin.
\end{abstract}

Keywords: electrophoresis, immune passive transfer, gammaglobulin, lamb

\section{INTRODUÇÃO}

Umas das grandes preocupações na criação de ovinos no Brasil e no mundo é a elevada taxa de mortalidade de cordeiros nos primeiros dias de

Recebido em 26 de dezembro de 2012

Aceito em 6 de dezembro de 2013

Autor para correspondência (correponding author)

E-mail: mege@uol.com.br vida, diminuindo os ganhos produtivos. Fatores como baixo peso ao nascimento, não ingestão do colostro, partos múltiplos, idade da ovelha e fatores relacionados ao ambiente, como temperatura e clima, afetam diretamente a sobrevivência dos cordeiros (Christley et al., 2003). 
Pouco se sabe do período ideal de absorção colostral pelo intestino de neonatos ovinos. Há relatos de aumento dos níveis de imunoglobulinas séricas quando a ingestão ocorre nas primeiras horas de vida e há grande decréscimo após 24 horas (Tizard, 2009). Isso se deve ao amadurecimento das células intestinais, ou melhor, à troca por uma primeira geração de células adultas, maduras, caracterizadas pela impermeabilidade a macromoléculas (Smeaton e Simpson-Morgan, 1985; Xu, 1996; Bessi et al., 2002ab; Kindlein et al., 2008).

A mudança no manejo de animais próximos ao parto deve ser assumida para que os recémnascidos sejam capazes de ficar em pé, procurar o úbere e sugar, vigorosamente, o colostro, que é fonte de nutrição, hidratação, proteção imunológica e energia (Dwyer e Morgan, 2006; Dwyer, 2008).

O colostro também sofre alterações na quantidade de imunoglobulinas, que diminuem gradativamente com o avançar da lactação (Mccarthy e Mcdougall, 1953; Hunter et al., 1977; Tizard, 2009). De acordo com Mellor e Murray (1986), essa mudança ocorre a partir das 18 horas da primeira mamada em ovelhas Scottish Blackface e Suffolk. Os cordeiros nascerão agamaglobulinêmicos e somente após seis meses de idade estarão aptos a debelarem infecções agudas por conta própria (Pugh, 2004).

Segundo Nunes (2006), em cordeiros mestiços da raça Santa Inês, considera-se falha de transferência quando a quantidade de imunoglobulinas $\mathrm{G}(\mathrm{IgG})$ presente no soro está abaixo de $500 \mathrm{mg} / \mathrm{dL}$, falha parcial quando está entre 500 e $1500 \mathrm{mg} / \mathrm{dL}$, e completa quando maior que $1500 \mathrm{mg} / \mathrm{dL}$. Em relação à quantidade IgG no colostro, a falha na transmissão é constatada quando a concentração está abaixo de $670 \mathrm{mg} / \mathrm{dL}$, enquanto uma boa transmissão apresenta valores de $\mathrm{IgG}$ superiores a $900 \mathrm{mg} / \mathrm{dL}$.

A determinação da proteína total por refratometria pode ser empregada com confiabilidade para identificar os indivíduos portadores de FTIP. O método é barato e simples e pode ser realizado no campo com resultados rápidos, bastando aguardar a retração do coágulo para a obtenção de um pequeno volume de soro. Seria possível considerar o valor de 5,1 a $6,0 \mathrm{~g} / \mathrm{dL}$ de proteína total como indicativo de falha parcial da transferência de imunidade passiva e o valor inferior ou igual a $5,0 \mathrm{~g} / \mathrm{dL}$ como indicativo de falha total da transferência de imunidade passiva nos cordeiros (Turquino et al., 2011).

Objetivou-se avaliar a transferência de imunidade passiva por meio da absorção colostral das imunoglobulinas pelo cordeiro, analisando a qualidade e quantidade de anticorpos disponíveis no colostro das ovelhas.

\section{MATERIAL E MÉTODOS}

Todos os procedimentos experimentais foram aprovados pela Comissão de Ética no Uso de Animais da Faculdade de Medicina Veterinária e Zootecnia, Campus de Botucatu, sob protocolo $\mathrm{n}^{\circ} 28 / 2009$.

O estudo foi realizado na área de Produção e Pesquisa de Leite Ovino na Fazenda Edgárdia, pertencente à Faculdade de Medicina Veterinária e Zootecnia da Unesp, no município de Botucatu, no estado de São Paulo, no período de maio a agosto de 2010 .

Foram colocadas em estação de monta 56 ovelhas da raça Bergamácia, em idade reprodutiva e menores que seis anos, multíparas. A partir do terço final de gestação, para facilitar o acompanhamento dos partos, as fêmeas foram confinadas em instalação coberta. As ovelhas, durante a gestação, foram mantidas em pastagem de Panicum maximum cv Tanzânia durante o dia, e à noite receberam suplementação de silagem de milho. Após o parto e dentro do barracão, passaram a receber ração para período de lactação, silagem de milho de fabricação própria, feno de braquiária triturado, sal mineral para ovinos e água ad libitum. Os recém-nascidos permaneceram com suas mães durante todo o período experimental.

Logo após o parto, aguardando o período de retirada dos envoltórios fetais, limpeza e formação de vínculo entre mãe e filhote, as fêmeas passaram por uma rápida sequência de exames: aferição de temperatura retal, frequência cardíaca e respiratória, movimentos ruminais e pesagem. Durante todo o tempo, o filhote foi mantido próximo a sua mãe, mas sem mamar o colostro. Esses procedimentos não ultrapassaram mais que 10 minutos e tiveram finalidade de acompanhamento clínico. A colheita de colostro 
foi realizada antes da primeira mamada com um pool de jatos dos dois tetos, não excedendo o volume de $50-60 \mathrm{~mL}$ por colheita em cada fêmea, utilizando-se copos coletores de tampa vermelha com volume máximo de $80 \mathrm{~mL}$.

Todas as colheitas foram realizadas em dois momentos: o primeiro sendo imediatamente após o parto e o segundo, 12 horas após. Os frascos foram identificados e levados ao freezer $-20^{\circ} \mathrm{C}$ para posterior análise em conjunto.

As amostras de colostro armazenadas em copo coletor foram descongeladas em banho-maria, $37^{\circ} \mathrm{C}$, até completa solubilização. Logo após, foram divididas em duas alíquotas, uma com o colostro puro para análise de densidade e outra para obtenção do soro lácteo, utilizado para proteína total (PT) e concentração de imunoglobulinas.

A concentração de proteína total do soro lácteo foi determinada pela técnica de biureto. $\mathrm{O}$ fracionamento das proteínas foi realizado por meio da eletroforese em gel de poliacrilamida $10 \%$ contendo dodecil sulfato de sódio (SDSPAGE), conforme técnica descrita por Laemmli (1970) e as recomendações de Baroza (2007). Para a determinação da densidade do colostro in natura, devido a sua grande viscosidade, não foi possível utilizar métodos comuns, como, por exemplo, o refratômetro. Também não se pôde usar o colostrômetro, pois a quantidade era muito pequena. A densidade foi, então, obtida empregando-se a fórmula: densidade $(\mathrm{g} / \mathrm{mL})=$ massa/volume. Comparações entre densidade do colostro e absorção colostral também foram verificadas.

Após o nascimento, evitou-se que o cordeiro mamasse o colostro para não alterar os resultados do estudo. Foi respeitado o período de limpeza e ligação entre mãe e filhote, só sendo afastados para os exames e colheitas necessárias, quando o filhote estivesse em estação por pelo menos cinco minutos. Logo após, o animal era devolvido à mãe e observado até que mamasse; caso houvesse rejeição, mesmo que momentânea, era forçada a ingestão do colostro. A colheita sanguínea nos neonatos foi feita por meio de punção da veia jugular de $3 \mathrm{~mL}$, em tubos a vácuo, e o sangue foi centrifugado por 10 minutos em 3500rpm. O soro foi mantido sob refrigeração a $4^{\circ} \mathrm{C}$ até a realização dos exames bioquímicos.

As colheitas foram realizadas em seis momentos: M0, sendo imediatamente após o parto (0h), M6 (6h), M12 (12h), M24 (24h), M36 (36h) e M48 (48h).

A determinação da proteína total sérica foi realizada em refratômetro, e as análises de concentração de imunoglobulinas totais e as frações foram obtidas por eletroforese em gel de poliacrilamida Nativa 7\%. Para a quantificação das $\gamma$-globulinas séricas dos cordeiros e colostrais, fez-se a multiplicação do valor total de proteínas (PT) pela porcentagem da fração gama encontrada na corrida eletroforética, resultando em valor numérico dessa concentração com unidade em $\mathrm{g} / \mathrm{dL}$.

Para a análise estatística das variáveis ligadas à eletroforese, como mobilidade relativa (Rf), porcentagem (\%) e dosagem das proteínas séricas, proteínas colostrais e densidade colostral, foi utilizado o programa Assistat Statistical (Silva e Azevedo, 2009). Para a interação entre as variáveis, foi utilizada ANOVA, com comparação entre os momentos de colheita e as frações eletroforéticas obtidas para proteínas sanguíneas, colostrais e densidade. Utilizou-se teste $t$ ao nível de $5 \%$ de probabilidade.

Nos dados referentes à densitometria de gamaglobulinas séricas, aplicou-se o teste de Bartlett para a homogeneidade das variâncias. Para as médias, empregou-se o teste de experimento inteiramente ao acaso, com probabilidades ao nível de $1 \%$ e $5 \%$, pois a interação se deu dentro do tratamento (momentos). Foi aplicado o teste $t$ para o soro sanguíneo e o teste de Duncan para o soro colostral, ambos com probabilidade de 5\%. A correlação de PT e gamaglobulina sérica dos cordeiros foi feita por meio do teste de Spearman do programa IBM/SPSS Statistics v.19.0.

\section{RESULTADOS E DISCUSSÃO}

As gamaglobulinas, foco principal deste estudo, estavam presentes em baixa concentração no soro dos cordeiros previamente à ingestão do colostro. Isso estabelece que os animais nasçam hipogamaglobulinêmicos, contrariamente ao 
descrito por grande parte dos autores que afirmam que os recém-nascidos da espécie ovina, assim como os bovinos, são agamaglobulinêmicos (Pugh, 2004; Barrington e Parish, 2006; Tizard, 2009). A presença de pequena quantidade de imunoglobulinas $(2,5 \%)$ deve-se à produção endógena, pois os cordeiros estão aptos a produzirem anticorpos ainda in utero, embora inespecíficos (Tizard, 2009). Após a mamada do colostro, ocorreu um aumento de oito vezes na quantidade de gamaglobulinas já nas primeiras seis horas $(19,5 \%)$ (Tab. 1), apresentando tendência à elevação até a estabilização dentro de 24 - 36 horas de vida.
Isso demonstrou a capacidade de absorção das proteínas colostrais, particularmente, as gamaglobulinas.

A porcentagem de gamaglobulina colostral sofreu um decréscimo com o passar das horas (Tab. 2), devido à transição do colostro para leite. As imunoglobulinas são excretadas no leite, mas em concentrações muito reduzidas, como exemplifica Maestá (2003), ao estudar a concentração de IgG no colostro de ovelhas alimentadas com diferentes dietas até as 48 horas pós-parto $(0,390 \pm 0,13 \mathrm{~g} / \mathrm{dL})$.

Tabela 1. Média e desvio-padrão da concentração das proteínas séricas pela refratometria (g/dL) e das frações gama, beta, alfaglobulina e albumina (\%) pela eletroforese Nativa a $7 \%$, em cordeiros ao nascimento e com seis, $12,24,36$ e 48 horas de vida

\begin{tabular}{lccccccccc}
\multicolumn{1}{c}{ Frações } & \multicolumn{3}{c}{ Gamaglobulina } & \multicolumn{2}{c}{ Betaglobulina } & Alfaglobulina & Albumina & Proteína \\
total
\end{tabular}

Em relação à proteína total, observou-se um acréscimo na concentração entre o nascimento (M0) $(4,46 \pm 0,58 \mathrm{~g} / \mathrm{dL})$ e 24 horas após $(5,68 \pm 0,89 \mathrm{~g} / \mathrm{dL})$ (Tab. 2), estabilizando-se logo após. Esses dados condizem com o descrito por Silva et al. (2007), que analisaram o soro de cordeiros mestiços e obtiveram resultados de
$3,62 \pm 0,7 \mathrm{~g} / \mathrm{dL}$ ao nascimento, com aumento para $6,77 \pm 1,20 \mathrm{~g} / \mathrm{dL}$ após 24 horas de vida. A elevação da concentração de proteína total demonstra a capacidade do neonato em absorver, em pouco tempo, grandes quantidades de proteínas e repassá-las à circulação.

Tabela 2. Média e desvio-padrão da concentração de gamaglobulina (g/dL) calculada com base na concentração de proteína total $(\mathrm{g} / \mathrm{mL})$ no colostro de ovelhas a partir do parto e 12 horas após

\begin{tabular}{lcccc} 
& \multicolumn{4}{c}{ Gamaglobulina } \\
\cline { 2 - 5 } Momentos & Média (X) \pm SD & Lim. conf. inf.* & Lim. conf. sup.** & Variância $\left(\mathrm{s}^{2}\right)$ \\
\hline Ao nascimento & $3,125 \pm 1,27$ & 2,61 & 3,64 & 1,62 \\
12 horas & $1,378 \pm 0,82$ & 1,04 & 1,71 & 0,68
\end{tabular}

**Lim. conf. inf. - Limite de confiança inferior da média (95\%); ***Lim.conf. sup. - Limite de confiança superior da média $(95 \%)$. 
A máxima absorção de imunoglobulinas colostrais, em bovinos, ocorre em torno de oito horas de vida, com queda pronunciada após esse período (Cortese, 2009). No presente estudo, o pico máximo de absorção estabeleceu-se entre 12 e 24 horas, não representando um prejuízo à imunidade dos cordeiros (Fig. 1) (Tab. 3). Uma explicação para o longo período de absorção nos ovinos pode ser a menor quantidade de colostro ingerido (100 a 200mL/dia), quando comparado à espécie bovina (dois a quatro litros/dia). O colostro, além de sua função imunológica, também estimula o fechamento das microvilosidades intestinais às macromoléculas. Portanto, quanto maior a quantidade ingerida, mais rápida será o desenvolvimento das células epiteliais intestinais, diminuindo, dessa forma, a absorção dos anticorpos maternos. Por outro lado, a rápida oclusão das fendas interepiteliais impede que agentes patogênicos adentrem $o$ organismo do neonato, levando a uma afecção (Tizard, 2009).

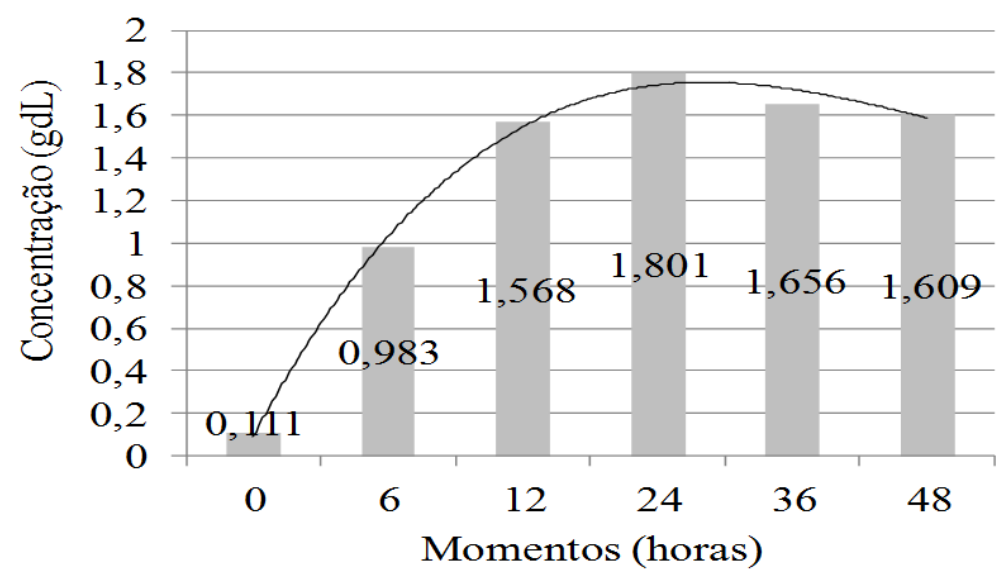

Figura 1. Concentração de gamaglobulina $(\mathrm{g} / \mathrm{dL})$ em cordeiros ao nascimento e com seis, 12, 24, 36 e 48 horas de vida.

Tabela 3. Média e desvio-padrão das concentrações de gamaglobulina (g/dL) e proteína total (g/dL) em cordeiros ao nascimento e com seis, $12,24,36$ e 48 horas de vida

\begin{tabular}{lcccc}
\hline \multirow{2}{*}{ Momentos } & \multicolumn{2}{c}{ Proteína total } & \multicolumn{2}{c}{ Gamaglobulina } \\
\cline { 2 - 5 } \multicolumn{1}{c}{ X $\pm \mathrm{s}$} & $\mathrm{s}^{2}$ & $\mathrm{X} \pm \mathrm{s}$ & $\mathrm{s}^{2}$ \\
\hline Ao nascimento & $4,46 \pm 0,58^{*^{\mathrm{a}}}$ & 0,33 & $0,111 \pm 0,0 *^{\mathrm{a}}$ & 0,005 \\
12 horas & $4,75 \pm 1,06^{* \mathrm{a}}$ & 1,12 & $0,983 \pm 0,61 *^{\mathrm{b}}$ & 0,38 \\
24 horas & $5,62 \pm 0,8 *^{\mathrm{b}}$ & 0,77 & $1,568 \pm 0,87 *^{\mathrm{c}}$ & 0,77 \\
36 horas & $5,68 \pm 0,8 *^{\mathrm{b}}$ & 0,79 & $1,801 \pm 0,86^{* \mathrm{c}}$ & 0,75 \\
48 horas & $5,19 \pm 1,6 *^{\mathrm{b}}$ & 2,72 & $1,656 \pm 0,8 *^{\mathrm{c}}$ & 0,66 \\
\hline
\end{tabular}

* Teste $t(\mathrm{p}<0,01)$, correlação linear. Médias seguidas pela mesma letra não diferem estatisticamente entre si dentro do grupo, teste $t$ ao nível de $5 \%$ de probabilidade.

Shubber e Doxey (1979) observaram que concentrações de imunoglobulinas maiores que $1,09 \mathrm{~g} / \mathrm{dL}$ após 30 horas de vida conferiam imunidade adequada ao cordeiro neonato. Feitosa et al. (2001), em um estudo em bovinos, comprovaram transferência efetiva da imunidade passiva, quando os valores eram superiores a $0,5 \mathrm{~g} / \mathrm{dL}$, sendo ideal acima de $1,6 \mathrm{~g} / \mathrm{dL}$ (Feitosa et al., 2003). Correlacionando os valores encontrados neste estudo nas primeiras 24 horas $(1,801 \pm 0,86 \mathrm{~g} / \mathrm{dL})$ (Tab. 3), os cordeiros obtiveram quantidades suficientes de imunoglobulinas colostrais para responderem adequadamente a infecções.

O uso da refratometria como método para avaliação da transferência de imunidade passiva em cordeiros revelou uma correlação positiva entre a concentração de proteína total e a concentração de globulinas séricas (Tab. 4). Assim, quanto maior o valor da proteína, maior presença de globulinas. 
Tabela 4. Correlação entre a concentração de proteína total e de gamaglobulina em cordeiros ao nascimento e com seis, $12,24,36,48$ horas de vida

\begin{tabular}{clccc}
\hline & \multicolumn{4}{c}{ Gamaglobulina } \\
\cline { 2 - 5 } \multicolumn{1}{c}{ Momentos } & Coef. correlação & Valor de P & N* $^{*}$ \\
\hline & Ao nascimento &, 091 &, 557 & 29 \\
& 6 horas &, $613 \mathrm{a}^{* *}$ &, 0001 & 29 \\
\multirow{3}{*}{ Proteína total } & 12 horas &, $884 \mathrm{a}$ &, 0001 & 29 \\
& 24 horas &, $934 \mathrm{a}$ &, 0001 & 27 \\
& 36 horas &, $921 \mathrm{a}$ &, 0001 & 29 \\
& 48 horas &, $910 \mathrm{a}$ &, 0001 & 28 \\
\hline
\end{tabular}

*N = número de indivíduos. ** Números seguidos pela mesma letra na coluna mostram significância $(\mathrm{P}<0,01)$.

As concentrações séricas de proteínas, antes da ingestão do colostro e após 24 horas, foram muito próximas às obtidas por Nunes (2006) para cordeiros nascidos de parto simples, respectivamente $4,649 \mathrm{~g} / \mathrm{dL}$ e $7,235 \mathrm{~g} / \mathrm{dL}$.

Silva et al. (2007) observaram aumento em torno de seis a 10 vezes na concentração de gamaglobulina após 24 a 72 horas da ingestão do colostro em cordeiros.

O valor encontrado ao nascimento $(0,32 \pm 0,12 \mathrm{~g} / \mathrm{dL})$ apresentou elevação acentuada para $3,39 \pm 1,13 \mathrm{~g} / \mathrm{dL}$. Esses dados condizem com os encontrados neste estudo, mesmo tendo a concentração de gamaglobulinas previamente à ingestão de colostro um valor menor ao descrito $(0,111 \pm 0,07 \mathrm{~g} / \mathrm{dL})$, embora apresentasse uma elevação de nove a 16 vezes após 24 horas $(1,801 \pm 0,86 \mathrm{~g} / \mathrm{dL})$ (Tab. 2). Essa diferença pode ser explicada pelas distintas metodologias aplicadas, pois a eletroforese Nativa deste estudo é mais sensível e específica do que a eletroforese em gel de agarose utilizada por Silva et al. (2007).

Por não haver métodos descritos para análise da densidade colostral em ovinos e não ser possível o uso do colostrômetro devido à quantidade insuficiente de material produzido utilizou-se a fórmula original da densidade $(\mathrm{d}=\mathrm{m} / \mathrm{v}) ; \quad \mathrm{o}$ intervalo variou de $1,056-1,086 \mathrm{~g} / \mathrm{dL}$ ao nascimento e de 1,050-1,078g/dL 12 horas pós-parto (M12) (Tab. 5). A concentração de gamaglobulina correspondente à densidade encontrada foi de $3,125 \pm 1,27 \mathrm{~g} / \mathrm{dL}$ e $1,378 \pm 0,82 \mathrm{~g} / \mathrm{dL}$, respectivamente. A densidade colostral foi semelhante à descrita para bovinos, conferindo uma imunidade adequada aos cordeiros, mesmo com concentrações de globulinas abaixo das descritas pela literatura. Em caprinos, a falha de transferência ocorre quando a concentração encontra-se abaixo de 1,21g/dL (Simões et al., 2005).

Em relação à densidade e aos níveis de gamaglobulina presentes no colostro, houve uma baixa correlação, embora positiva ao nascimento e 12 horas após o parto, ou seja, com o aumento da fração gama de acordo com a densidade. Nunes (2006) também observou correlação positiva $(r=0,35)$ em ovinos de corte.

Observou-se um declínio na concentração de gamaglobulina entre o nascimento e 12 horas após o parto (de 3,125 $\pm 1,27$ para $1,378 \pm 0,82 \mathrm{~g} / \mathrm{dL}$ ) (Fig. 2) (Tab. 5), o que demonstra a importância na ingestão de colostro neste período devido à grande disponibilidade de anticorpos. Como o colostro não foi analisado após 12 horas, não se verificou a diminuição na quantidade de gamaglobulinas após esse período. Esses dados são semelhantes aos descritos por Fernandes (2005), sendo a maior concentração de gamaglobulina encontrada logo após o parto $(8,48 \pm 1,03 \mathrm{~g} / \mathrm{dL})$, decaindo até a quinta parte após 24 horas $(0,88 \pm 0,33 \mathrm{~g} / \mathrm{dL})$.

A concentração de globulinas no soro dos cordeiros após 24 horas (M24) foi de $1,801 \pm 0,86 \mathrm{~g} / \mathrm{dL}$, semelhante ao encontrado por Hunter et al. (1977), que descreveram a concentração de imunoglobulinas menor que $1,5 \mathrm{~g} / \mathrm{dL}$ no primeiro dia de vida. Portanto, ao nascimento, os cordeiros são hipogamaglobulinêmicos, sendo a falha de transferência de imunidade passiva considerada em concentrações de imunoglobulinas inferiores a $0,5 \mathrm{~g} / \mathrm{dL}$, de acordo com Nunes (2006). 
Avaliação da absorção...

Tabela 5. Média e desvio-padrão da concentração de gamaglobulina (\%) (eletroforese SDS a 10\%), proteína total $(\mathrm{g} / \mathrm{mL})$ (espectrofotometria) e densidade $(\mathrm{g} / \mathrm{dL})$ no colostro de ovelhas a partir do parto e 12 horas após

\begin{tabular}{lcccc}
\hline \multirow{2}{*}{ Momentos } & \multicolumn{4}{c}{ Gamaglobulina } \\
\cline { 2 - 5 } Ao nascimento & $3,125 \pm 1,27$ & 2,61 & Lim. conf. sup. ${ }^{*}$ & Variância $\left(\mathrm{s}^{2}\right)$ \\
\hline 2 horas & $1,378 \pm 0,82$ & 1,04 & 1,71 & 1,62 \\
& \multicolumn{5}{c}{ Proteína total } \\
\hline Ao nascimento & $6,26 \pm 1,96$ & 5,48 & 7,04 & 31,35 \\
12 horas & $3,77 \pm 1,46$ & 3,19 & 4,35 & 2,13 \\
\hline \multicolumn{5}{c}{ Densidade } \\
\hline Ao nascimento & $1,056 \pm 1,086$ & 1,063 & 1,077 & 0,0002 \\
12 horas & $1,050 \pm 1,078$ & 1,058 & 1,070 & 0,0002 \\
\hline
\end{tabular}

*Lim. conf. inf. - Limite de confiança inferior da média (95\%); **Lim.conf. sup. - Limite de confiança superior da média $(95 \%)$.

\section{CONCLUSÕES}

A partir do nascimento, ocorreu aumento progressivo na concentração de proteína total e de gamaglobulina, o que demonstra a absorção colostral sérica em cordeiros da raça Bergamácia, com estabilização dos níveis séricos após 24 horas. Portanto, não é necessário que se force a amamentação, caso esta não ocorra nas primeiras horas de vida. As concentrações de gamaglobulina acima de $1,5 \mathrm{~g} / \mathrm{dL}$ indicam uma boa transferência de imunidade passiva em cordeiros. A refratometria provou ser um método adequado para se avaliar a transferência de imunidade passiva, ao demonstrar correlação positiva entre a concentração de proteína total e de gamaglobulina séricas. $\mathrm{O}$ declínio da quantidade de proteína total e da densidade colostral está estritamente relacionado com a diminuição na concentração de gamaglobulinas.

\section{REFERÊNCIAS}

BAROZA, P.F.J. Proteínas, enzimas e minerais na secreção láctea de cabras e vacas, nos primeiros 30 dias pós-parto, congelada ou não. 2007. 113f. Dissertação (Mestrado em Medicina Veterinária) - Faculdade de Ciências Agrárias e Veterinárias, Universidade Estadual Paulista, Jaboticabal. 2007.

BARRINGTON, G.M.; PARISH, S.M. Doenças de Imunodeficiência dos Ruminantes. In: SMITH, B.P. (Ed). Medicina Interna de Grandes Animais. 3.ed. São Paulo: MANOLE. p.16001602, 2006.
BESSI, R.; PAULETTI, P.; D'ARCE, R.D.; MACHADO NETO, R. Absorção de anticorpos do colostro em bezerros. I. Estudo no intestino delgado proximal. Rev. Bras. Zootec., v.31, p.2314-2324, 2002a.

BESSI, R.; PAULETTI, P.; D’ARCE, R.D.; MACHADO NETO, R. Absorção de anticorpos do colostro em bezerros. II. Estudo no intestino delgado distal. Rev. Bras. Zootec., v.31, p.23252331, 2002b.

CHRISTLEY, R.M.; MORGAN, K.L.; PARKIN, T.D.H. et al. Factors related to the risk of neonatal mortality, birth-weight and serum immunoglobulin concentration in lambs in the UK. Prev. Vet. Med., v.57, p.209-226, 2003.

CORTESE, V.S. Neonatal Immunology. Bovine Neonatology. Vet. Clin. North Am. Food Anim. Pract., v.25, p.221-228, 2009.

DWYER, C.M. The welfare of the neonatal lamb. Small Rumin. Res., v.76, p.31-41, 2008.

DWYER, C.M.; MORGAN, C.A. Maintenance of body temperature in the neonatal lamb: Effects of breed, birth weight, and litter size. $J$. Anim. Sci., v.84, p.1093-1101, 2006.

FEITOSA, F.L.F.; BIRGEL, E.H.; MIRANDOLA, R.M.S.; PERRI, S.H.V. Diagnóstico de falha de transferência de imunidade passiva em bezerros através da determinação de proteína total e frações eletroforéticas, imunoglobulinas $\mathrm{G}$ e $\mathrm{M}$ e da atividade da gama glutamil transferase no soro sanguíneo. Cienc. Rural., v.31, p.251-55, 2001. 
FEITOSA, F.L.F.; BORGES, A.S.; BENESI, F.J. et al. Concentração de imunoglobulinas G e M no soro sanguíneo de bezerros da raça holandesa até os 90 dias de idade. Braz. J. Vet. Res. Anim. Sci., v.40 (supl. 1), p.26-31, 2003.

FERNANDES, S. Efeitos da nutrição $e$ da idade à desmama sobre o desempenho, qualidade do colostro e do leite e incidência de mastite subclínica em ovelhas da raça Santa Inês. 2005. 72f. Dissertação (Mestrado em Medicina Veterinária) - Faculdade de Medicina Veterinária e Zootecnia, Universidade Estadual Paulista. Botucatu. 2005.

HUNTER, A.G.; RENEAU, J.K.; WILLIAMS, J.B. Factors affecting IgG concentration in dayold lambs. J. Anim. Sci., v.45, p.1146-1151, 1977.

KINDLEIN, L.; PAULETTI, P.; BAGALDO, A.R. et al. Efeito da suplementação de colostro enriquecido sobre as características morfológicas da mucosa intestinal de bezerros neonatos. Acta Sci. Vet., v.36, p.31-34, 2008.

LAEMMLI, U.K. Cleavage of structural proteins during the assembly of the head of bacteriophage T4. Nature. v.227, p.680-685, 1970.

MAESTÁ, S.A. Desempenho produtivo, composição química e concentração de $\operatorname{Ig} G$ do colostro e do leite de ovelhas e cordeiros de corte sob distintos níveis de proteína e energia. 2003. 62f. Tese (Doutorado em Zootecnia) Faculdade de Medicina Veterinária e Zootecnia, Universidade Estadual Paulista. Botucatu, SP.

MCCARTHY, E.F.; MCDOUGALL, E.I. Absorption of immune globulin by the young lamb after ingestion of colostrum. Biochem. J., v.55, p.177-182, 1953.

MELLOR, D.J.; MURRAY, L. Making the most of colostrum at lambing. Vet. Rec. v.118, p.351353, 1986.

NUNES, A.B.V. Estudo da transmissão da imunidade passiva e da mortalidade em cordeiros mestiços de Santa Inês, na região norte de Minas Gerais. 2006. 86f. Dissertação (Mestrado em Medicina Veterinária) - Escola de Veterinária, Universidade Federal de Minas Gerais, Belo Horizonte. 2006.

PUGH, D.G. Clínica de Ovinos e Caprinos. São Paulo: ROCA. 513p, 2004.

SHUBBER, A.H.; DOXEY, D.L. Immunoglobulin levels in ewe colostrum and in lamb serum. Res. Vet. Sci., v.27, p.283-285, 1979.

SILVA, F.A.S.E.; AZEVEDO, C.A.V. Principal Components Analysis in the Software AssistatStatistical Attendance. In: World Congress On Computers In Agriculture, 7, Anais... USA: American Society of Agricultural and Biological Engineers. 2009.

SILVA, D.F.M.; COSTA, J.N.; ARAUJO, A.L. et al. Serum proteinogram concentration in crossbred lambs (Santa Inês x Dorper) from birth until 90 days old: effect of the age and ingestion of colostrums monitoring. Arch. Vet. Sci., v.12, p.86-87, 2007.

SIMÕES, S.V.D.; COSTA, R.G.; SOUZA, P.M. et al. Imunidade passiva, morbidade neonatal e desempenho de cabritos em diferentes manejos de colostro. Pesqui. Vet. Bras., v.25, p.219-224, 2005.

SMEATON, T.C.; SIMPSON-MORGAN, M.W. Epithelial cell renewal and antibody transfer in the intestine of the foetal and neonatal lamb. Aust. J. Exp. Biol. Med. Sci., v.63, p.41-51, 1985.

TIZARD, I.R. Imunologia Veterinária: Uma Introdução. São Paulo: ROCA. 608p, 2009.

TURQUINO, C.F.; FLAIBAN, K.K.M.C.; LISBÔAA, J.A.N. Transferência de imunidade passiva em cordeiros de corte manejados extensivamente em clima tropical. Pesq. Vet. Bras., v.31, p.199-205, 2011.

XU, R.J. Development of the newborn GI tract and its relation to colostrum/milk intake: a review. Repr. Fertility Develop., v.8, p.35-48, 1999. 